\title{
Cholinergic blockade in the prevention of exercise-induced asthma
}

\author{
J P R HARTLEY AND B H DAVIES \\ From the Asthma Research Unit, Sully Hospital, Sully, South Glamorgan
}

ABSTRACT The contribution of vagal mechanisms to exercise-induced asthma has been studied $\dot{\omega}^{\circ}$ in 10 adult asthmatic patients using the anticholinergic drug ipratropium bromide. Exercise tests ${ }^{\infty}$ were performed for eight minutes on a cycle ergometer and each individual's tests were standardised 은 by matching oxygen uptake. Two tests were done on each of three study days, the first being without $\rightarrow$ previous medication, and the second preceded by inhalation of ipratropium bromide, $0 \cdot 1$, or $1 \mathrm{mg} \mathcal{D}_{\mathcal{D}}$

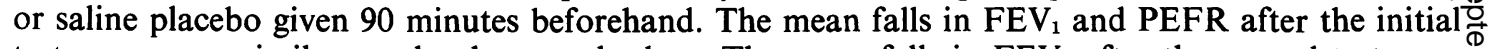
tests were very similar on the three study days. The mean falls in $\mathrm{FEV}_{1}$ after the second test were 3 $22.3 \%, 19.5 \%$, and $12.5 \%$ with placebo, $0.1 \mathrm{mg}$, and $1 \mathrm{mg}$ ipratropium bromide respectively. Only the higher dose was significantly better than placebo. The results were also analysed using $\vec{\bullet}$ a protection index to compare the first and second tests each day and $1 \mathrm{mg}$ ipratropium bromide $0_{0}^{\circ}$ was significantly better than both $0.1 \mathrm{mg}$ and placebo. Similar results were obtained using PEFR. Equal bronchodilatation was produced by the two doses of drug. We conclude that conventional doses of anticholinergic drugs are not effective in preventing exercise-induced asthma, while large doses may do so in the same group of subjects.

There is now considerable evidence that the vagus nerve is important in modifying the response to various forms of airway challenge in asthmatic individuals. In man, anticholinergic drugs have been reported to reduce the bronchial response to antigen challenge ${ }^{12}$ as well as to agents which are thought to stimulate airway irritant receptors directly, such as citric acid, cold air, and dust. ${ }^{3}$

The ability of anticholinergic drugs to prevent exercise-induced asthma (EIA) has been debated since Jones and his co-workers ${ }^{4}$ demonstrated that atropine inhibited it partially in four out of six children. Subsequent studies using atropine have given conflicting results ${ }^{5-9}$ but have shown some protection from EIA in a proportion of subjects. Tinkelman et al ${ }^{10}$ suggested that the doses of atropine which had previously been used were inadequate and reported suppression of EIA in 17 of 18 children using large doses of inhaled atropine.

Ipratropium bromide (IB) is a newer anticholinergic drug which is a quarternary tropane alkaloid derivative of atropine. It has several

Address for reprint requests: Dr JPR Hartley, Asthma Research Unit, Sully Hospital, Sully, South Glamorgan. advantages over atropine sulphate, particularly $\overrightarrow{\vec{O}}$ when used in moderately high doses. It does not 3 cross the blood-brain barrier, has very little antihistaminic activity, is longer-acting, and its relative potency on bronchial smooth muscle is $₹$ greater than on other target organs such as $\frac{0}{d v}$ salivary glands. ${ }^{11} 12$

Several reports have failed to show any benefit $\frac{0}{3}$ in EIA from standard bronchodilator doses of 0 04-0.08 mg IB, ${ }^{13-15}$ although larger doses have $\frac{\mathrm{O}}{3}$ been effective in about half the subjects

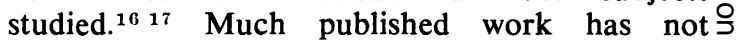
separated the effect of bronchodilatation from $\rightarrow$ specific antagonism of EIA. Not only can bronchodilatation alter airway reactivity ${ }^{18}$ but failure $N$ to measure it before exercise challenge can produce an incorrect assessment of post-exertional $\mathrm{N}$ bronchoconstriction if reference is made only to $\omega$ a pre-drug baseline. We have attempted to overcome these problems in studying the effects of $\stackrel{C}{E}$ $0.1 \mathrm{mg}$ and $1 \mathrm{mg}$ IB compared with placebo in a group of adults with EIA.

\section{Subjects and methods}

Four men and six women, age range 21-48 years $\stackrel{\square}{\stackrel{Q}{Q}}$ (mean 32 years), gave their informed consent to 
the study. All had reversible airflow obstruction and were known to have exercise-induced asthma $\left(>15 \%\right.$ fall in FEV $_{1}$ after a standard eight minute exercise test). Eight of the subjects had positive immediate skin prick tests to common allergens. Three subjects used inhaled beclomethasone dipropionate regularly, which was continued throughout the study, and one subject took sodium cromoglycate which was discontinued 24 hours before each test. Bronchodilator drugs were not taken within 12 hours of exercise challenge.

The patients attended the laboratory on three occasions. At each visit, two exercise tests were performed. The initial test was without premedication and was used to indicate the presence and severity of EIA on that study day. The second test was carried out two to three hours later (the exact time being constant for each individual), 90 minutes after the inhalation of IB, $0.1 \mathrm{mg}$, $1 \mathrm{mg}$, or placebo (saline). These treatments were administered single-blind and in random order from a De Vilbiss No 65 ultrasonic nebuliser. The patients wore a nose-clip and inhaled the nebulised solution through a mouthpiece and one-way valve for approximately six minutes using quiet tidal breathing until the required amount had been given. At 30 second intervals a single breath to vital capacity was taken and held for three seconds. The interval of 90 minutes between the treatments and the second exercise test was in order to allow maximum bronchodilatation to occur, so that a stable second baseline was reached.

Steady state submaximal exercise tests were performed on an electromagnetically-braked cycle ergometer (Lode) as previously described. ${ }^{1920}$ All patients cycled for eight minutes, during which time their oxygen uptake was recorded progressively on a graph. The work load was sufficient to raise the heart rate during the last minute of exercise to approximately $80 \%$ of the age-predicted maximum. ${ }^{21}$ Repeated exercise tests were standardised by matching oxygen uptake to within $5 \%$ by adjusting the ergometer setting as exercise progressed.

Ventilatory function was assessed by recording the peak expiratory flow rate (PEFR, Wright peak flow meter) and forced expiratory volume in one second $\left(\mathrm{FEV}_{1}\right.$, Vitalograph dry wedge spirometer). The best of three readings was recorded each time. Measurements were made five minutes and immediately before exercise and the means of these values used as the baseline. They were repeated immediately after exercise and at five-minute intervals thereafter for 30 minutes. Predicted normal values have been taken from Cotes. ${ }^{22}$

Failure to achieve a reduction of $\geqslant 15 \%$ in either PEFR or FEV 1 after the first, drug-free, exercise test at each visit resulted in the patient being asked to attend on another occasion and in this way it was hoped to minimize the effect of variation of EIA with time. The results have been expressed in terms of maximal \% fall in PEFR or FEV ${ }_{1}$ from the initial values immediately before exercise $([b-a / b] \times 100)$ where $b$ is the value before exercise, and $a$ is the minimum value after exercise. Statistical analysis has been carried out on $\log _{e} a / b$ using paired $t$ tests for inter-treatment comparisons of the second test each day. The difference between the degree of EIA induced by the first and second exercise tests at each visit has also been compared for each treatment day. For this a "percent protection index" 923 has been used by which the difference between the percentage fall in PEFR or FEV 1 after test 1 and test 2 on each treatment day are expressed as a percentage of the fall after test 1 . Using this method, a fall of $40 \%$ after test 1 followed by a fall of $10 \%$ after test 2 on the same day would represent $75 \%$ protection. The degree of protection given by each treatment has been compared by $t$ test. This method of analysis has been used in addition to the more straightforward comparison in order to minimise inter-day variations in EIA because of altered environmental conditions. All exercise tests were done in a laboratory at a temperature of $20-24^{\circ} \mathrm{C}$, but humidity was not controlled and it is assumed that this would vary less in three hours than over several days.

\section{Results}

The exercise performance in terms of mean oxygen uptake and minute ventilation is shown in table 1. There was no significant difference between these values for any of the six exercise tests on the three days of the study.

Table 1 Exercise performance during eight minutes cycling (mean values \pm SEM)

\begin{tabular}{llll}
\hline Day & Test & $\begin{array}{l}\text { Total oxygen uptake } \\
(\mathrm{mmol})^{*}\end{array}$ & $\begin{array}{l}\text { Total ventilation } \\
\text { (litres BTPS) }\end{array}$ \\
\hline Saline & 1 (pre) & $620 \pm 25$ & $357 \pm 20$ \\
& 2 (post) & $621 \pm 26$ & $347 \pm 21$ \\
IB 0.1 $\mathrm{mg}$ & 1 & $621 \pm 22$ & $346 \pm 16$ \\
& 2 & $612 \pm 23$ & $350 \pm 19$ \\
IB 1 $\mathrm{mg}$ & 1 & $612 \pm 23$ & $353 \pm 17$ \\
& 2 & $614 \pm 22$ & $349 \pm 22$ \\
\hline
\end{tabular}

*Multiply by 22.4 to convert to $\mathrm{ml}$. 
Values for FEV 1 and PEFR, before and after each exercise test are shown in table 2 , and for $\mathrm{FEV}_{1}$ also in the figure. The mean values for both measurements were very similar before the first exercise test (test 1) on each study day. On the placebo day, the initial mean $\mathrm{FEV}_{1}$ was 2.41 litres, $77.6 \%$ of the mean predicted value (range 53-113\%). The initial PEFR was 377 litres/ minute, $77.5 \%$ of the mean predicted value (range $54-109 \%$ ).

The level of ventilatory function before the second exercise test (test 2) gives a measure of the bronchodilatation produced by IB. If this value is compared with the level before the first test on the same day, then bronchodilatation was significant for $0.1 \mathrm{mg}$ and $1 \mathrm{mg}$ IB for both $\mathrm{FEV}_{1}$ and PEFR. There was no significant difference between the levels of ventilatory function before each exercise test on the day the placebo was given. No greater degree of bronchodilatation was produced by the larger dose of IB compared with the smaller dose.

Table 3 illustrates the effect of exercise on each subject in terms of the percentage fall in

Figure Mean FEV, values before and after exercise for six tests on three separate days. Arrows indicate inhalation of placebo or IB between exercise tests.

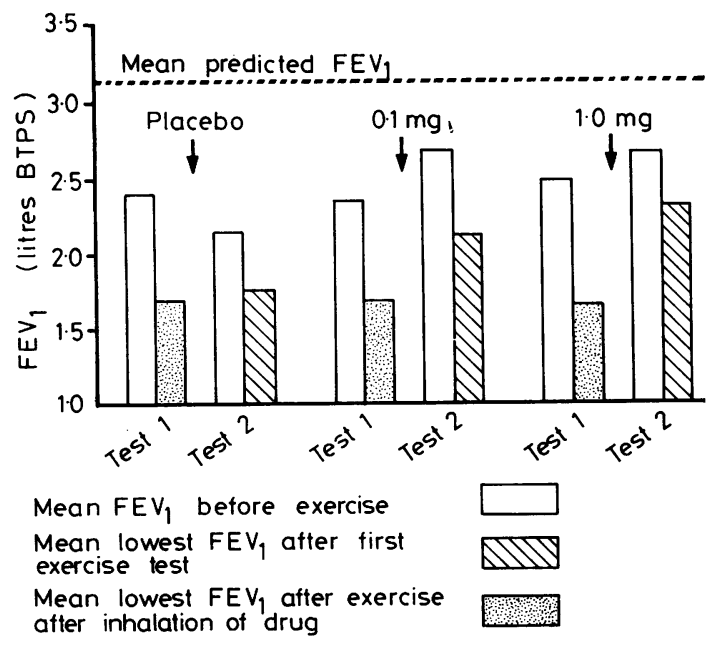

FEV $_{1}$ after each exercise test. There was no significant difference between the falls in $\mathrm{FEV}_{1}$ 음 produced by the first exercise test on each day. $\frac{\bar{c}}{7}$ The mean percentage falls in $\mathrm{FEV}_{1}$ were $29 \cdot 2, \stackrel{\mathbb{\Phi}}{\varrho}$ $29 \cdot 0$, and $33 \cdot 2 \%$ on placebo, $0.1 \mathrm{mg}$ IB and $1 \mathrm{mg} \%$ IB days respectively.

The second exercise test, 90 minutes after drug $\vec{\circ}$ administration gives a measure of the protective $\vec{\omega}$

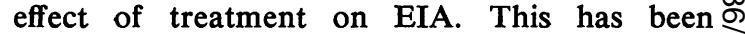
examined in two ways-firstly, with a compari- $\vec{x}$ son of the fall in $\mathrm{FEV}_{1}$ after placebo with the falls after each dose of IB, and secondly, by using the percentage protection index (see methods).

There was no significant difference between 을 placebo and $0.1 \mathrm{mg}$ IB in the fall in $\mathrm{FEV}_{1}$ after exercise (figure and table 3 ), but there was a $\$$ significant difference between placebo and $1 \mathrm{mg}$ 零 IB $(p=0.007)$. The difference between the two $\frac{\mathbb{D}}{3}$ doses of IB was not significant $(p=0 \cdot 11)$.

Using the percentage protection index, shown at the foot of table 3 , only the high dose of IB $\ddot{\odot}$ was significantly better than placebo $(p=0.003)$. However, this dose was now also significantly better than the lower dose of IB $(p=0.02)$.

Values for $\mathrm{FEV}_{1}$ only have been shown in the figure and table 3 . The results using PEFR were similar, the percentage protection figures for $\stackrel{\circ}{\Phi}$ placebo, $0.1 \mathrm{mg} \mathrm{IB}$ and $1 \mathrm{mg}$ IB being $22.0,44.4 \stackrel{2}{\overrightarrow{7}}$ and $64.5 \%$ respectively.

Table 3 Fall in FEV, after exercise (\%). Values for both exercise tests on each study day are shown

\begin{tabular}{|c|c|c|c|c|c|c|}
\hline \multirow{2}{*}{ Patient } & \multicolumn{2}{|l|}{ Placebo } & \multicolumn{2}{|c|}{$0.1 \mathrm{mg} \mathrm{IB}$} & \multicolumn{2}{|c|}{$I \mathrm{mg} I B$} \\
\hline & $\overline{\text { Test } 1}$ & Test 2 & Test I & $\overline{T e s t ~} 2$ & Test 1 & Test \\
\hline 1 & $29 \cdot 4$ & 10.9 & $26 \cdot 1$ & 9.6 & $31 \cdot 1$ & $7 \cdot 4$ \\
\hline 2 & $20 \cdot 0$ & $8 \cdot 2$ & $24 \cdot 0$ & $2 \cdot 1$ & $40 \cdot 3$ & $4 \cdot 4$ \\
\hline 3 & 54.9 & $34 \cdot 8$ & $30 \cdot 0$ & $18 \cdot 3$ & $44 \cdot 9$ & $27 \cdot 2$ \\
\hline 4 & $44 \cdot 3$ & $46 \cdot 6$ & $42 \cdot 7$ & $49 \cdot 3$ & $35 \cdot 4$ & $33 \cdot 3$ \\
\hline 5 & $33 \cdot 1$ & $31 \cdot 5$ & $39 \cdot 7$ & 44.9 & $47 \cdot 1$ & $15 \cdot 7$ \\
\hline 6 & $20 \cdot 4$ & $19 \cdot 3$ & $20 \cdot 2$ & $7 \cdot 2$ & $33 \cdot 1$ & 2.6 \\
\hline 7 & $29 \cdot 7$ & $22 \cdot 4$ & 34.4 & $12 \cdot 2$ & $23 \cdot 2$ & $2 \cdot 4$ \\
\hline 8 & $18 \cdot 0$ & $15 \cdot 7$ & $27 \cdot 8$ & $15 \cdot 2$ & $33 \cdot 3$ & $23 \cdot 6$ \\
\hline 9 & $17 \cdot 0$ & 16.9 & 22.9 & $14 \cdot 7$ & $22 \cdot 2$ & $1 \cdot 5$ \\
\hline 10 & $25 \cdot 3$ & $16 \cdot 7$ & $21 \cdot 7$ & $21 \cdot 2$ & $21 \cdot 6$ & 6.9 \\
\hline Mean & $29 \cdot 2$ & $22 \cdot 3$ & $29 \cdot 0$ & $19 \cdot 5$ & $33 \cdot 2$ & $12 \cdot 5$ \\
\hline SEM & $3 \cdot 9$ & $3 \cdot 8$ & $2 \cdot 4$ & 4.9 & 2.9 & $3 \cdot 7$ \\
\hline \multicolumn{2}{|c|}{$\%$ Protection } & $23 \cdot 6$ & & $37 \cdot 7$ & & $64 \cdot 6$ \\
\hline
\end{tabular}

Table 2 Initial values for FEV, and PEFR before exercise (B) and minimum values after exercise (A), (mean $\pm S E M)$. Values for both exercise tests on each study day are shown

\begin{tabular}{|c|c|c|c|c|c|c|c|}
\hline & & \multicolumn{2}{|l|}{ Placebo } & \multicolumn{2}{|l|}{$0.1 \mathrm{mg} \mathrm{IB}$} & \multicolumn{2}{|l|}{$I m g I B$} \\
\hline & & $B$ & $A$ & $B$ & $\boldsymbol{A}$ & $\boldsymbol{B}$ & $\boldsymbol{A}$ \\
\hline $\begin{array}{l}\text { FEV1 } 1 \\
\text { PEFR }\end{array}$ & $\begin{array}{l}\text { Test } 1 \text { (before drug) } \\
\text { Test } 2 \text { (after drug) } \\
\text { Test } 1 \\
\text { Test } 2\end{array}$ & $\begin{array}{c}2 \cdot 41 \pm 0 \cdot 09 \\
2 \cdot 21 \pm 0 \cdot 10 \\
377 \pm 10 \\
349 \pm 16\end{array}$ & $\begin{array}{c}1 \cdot 69 \pm 0 \cdot 09 \\
1 \cdot 74 \pm 0 \cdot 13 \\
263 \pm 16 \\
274 \pm 19\end{array}$ & $\begin{array}{l}2 \cdot 35 \pm 0 \cdot 12 \\
2 \cdot 70 \pm 0 \cdot 14 \\
367 \pm 15 \\
416 \pm 21\end{array}$ & $\begin{array}{c}1 \cdot 67 \pm 0.09 \\
2 \cdot 21 \pm 0.19 \\
253 \pm 13 \\
349 \pm 29\end{array}$ & $\begin{array}{l}2 \cdot 53 \pm 0 \cdot 12 \\
2 \cdot 69 \pm 0 \cdot 11 \\
388 \pm 15 \\
419 \pm 15\end{array}$ & $\begin{array}{c}1 \cdot 68 \pm 0 \cdot 11 \\
2 \cdot 35 \pm 0 \cdot 13 \\
254 \pm 21 \\
365 \pm 22\end{array}$ \\
\hline
\end{tabular}


No adverse effects were experienced with either dose of IB.

\section{Discussion}

Although the mechanisms of EIA remain largely unknown, much recent interest has centred on the vagus nerve. There is evidence that the vagus may be important in allergen-induced asthma in man, ${ }^{12}$ although this is still disputed. ${ }^{24}$ Evidence for vagai involvement has usually been sought by using the anticholinergic drugs atropine and, more recently, IB.

Therc. have been a large number of studies on the effect of these agents on EIA, and, almost 20 years since the first study, the evidence, and its interpretation, are still conflicting. Early studies used atropine in doses of 0.007$0.03 \mathrm{mg} / \mathrm{kg}$ given parenterally, ${ }^{4-7}$ and although the investigators generally were not impressed, EIA was suppressed or abolished in nine out of 22 subjects studied. Simonsson and his coworkers $^{8}$ found inhaled atropine effective in six out of nine subjects and subsequent studies have usually used this method of administration. Nevertheless, other workers found rather poor protection from EIA in both children ${ }^{25}$ and adults. $^{26}$ Tinkelman and his co-workers ${ }^{10}$ suggested that most studies had used inadequate doses of atropine and found a good reduction in EIA in 17 of 18 children using $0.1 \mathrm{mg} / \mathrm{kg}$ of atropine (approximately four to five times greater than doses used previously). This study is difficult to interpret because the effect of bronchodilatation was not taken into account, and it differs considerably from other studies in the degree of protection afforded by atropine. Godfrey and König ${ }^{9}$ found significant protection in seven children using atropine methonitrate aerosol, although only four of the individuals responded.

The effect of the newer anticholinergic drug IB was first reported in $1972^{13}$ and studies using $0.04-0.08 \mathrm{mg}$, the usual amount required when the drug is used as a bronchodilator, have shown little effect on EIA, ${ }^{13-15}$ with one exception. ${ }^{27}$ Larger doses of IB have been used with more consistent effects. McFadden and his co-workers ${ }^{16}$ gave enough IB by inhalation to block the bronchoconstrictor response to $1 \%$ methacholine challenge, and found inhibition of EIA in five out of 12 subjects, and Thomson and his colleagues $^{17}$ gave $2 \mathrm{mg}$ IB and found that eight out of 13 subjects were protected.

Thus there has been considerable variation in the reported response to cholinergic blockade. Some of this relates to dosage and method of administration, and some to the fact that anticholinergic drugs are bronchodilators with a rather slow onset of action and time should be allowed for a stable higher level of lung function to be reached before any interpretation of a post-exercise reduction can be made. Most studies have used small numbers of subjects and, if the degree of vagal importance in EIA is variable between individuals, chance selection could have accounted for some of the anomalies described between different studies. We have attempted to overcome this by using two very different doses of IB in the same individuals to see if there is a subgroup of "vagal responders" who are protected by a relatively small dose of anticholinergic drug, or if vagal factors are more widespread provided that enough anticholinergic drug is used to demonstrate it. We have allowed 90 minutes to elapse between drug administration and exercise challenge to ensure stable ventilatory function with which to compare deterioration after exercise.

The present study has shown that $0 \cdot 1 \mathrm{mg}$ IB is not sufficient to reduce EIA in most subjects and does not differ significantly from placebo. This dose is of the same order as that given for bronchodilatation (0.04-0.08 mg) and our results are in accord with previous studies. ${ }^{13-15}$ The degree of apparent placebo response is similar to that found by Wallace and Grieco, ${ }^{23}$ and is not unusual in EIA. ${ }^{9}$ A larger dose of IB, $1 \mathrm{mg}$, did produce reduction in EIA which was significant for the whole group, but which reflected the response of five individuals of the 10 subjects tested. In two of them there appeared to be a dose-response effect in that $0.1 \mathrm{mg}$ IB also reduced EIA, although not quite as markedly as $1 \mathrm{mg}$. In the remaining three cases there was no indication from the responses after the lower dose of drug that EIA would be prevented by the higher dose.

Interestingly, the two doses of IB produced the same degree of bronchodilatation, while differing in their ability to prevent EIA. We interpret these results to indicate that resting vagal tone can be abolished by conventional doses of anticholinergic drugs (0.04-0.1 mg IB), leading to bronchodilatation, but that such doses may not be adequate to block a large increase in vagal tone after exercise. This may only be possible using doses 20-25 times greater.

This interpretation presupposes that IB was acting only as an anticholinergic drug in both the doses used, and this is probably the case in view of its known pharmacology. ${ }^{11} 12$ Another possible explanation would be that $1 \mathrm{mg}$ IB had 
a greater bronchodilator effect than $0 \cdot 1 \mathrm{mg}$ IB, but that we failed to observe this by measuring only PEFR and FEV F $_{1}$ An increase in the size of large central airways could change airway reactivity and might also alter heat exchange across them (see below). Since PEFR and FEV predominantly reflect large airway calibre, although not being as sensitive as plethysmographic measurements of airways resistance, we think it unlikely that large differences occurred of which we were unaware. There have, however, been no detailed reports of the bronchodilator effects of two doses of IB similar to those we used.

These findings suggest that in half our group of subjects, vagal reflexes were important in mediating EIA. It is difficult to know whether different mechanisms were operating in the other five subjects, or whether we failed to achieve adequate cholinergic blockade even with $1 \mathrm{mg}$ IB. Thomson and his co-workers ${ }^{17}$ only found eight subjects out of 13 whose EIA was blocked by twice this dose, and it would appear that present techniques using cholinergic blockade will only show vagal mechanisms to be important in half to two-thirds of subjects with EIA.

The trigger for initiating a vagal reflex when one is present is also uncertain. Recent work has suggested that the primary event in EIA may be cooling of the airway mucosa subsequent upon exercise hyperventilation. ${ }^{28}{ }^{29}$ It is possible that this stimulates airway irritant receptors, leading to reflex bronchoconstriction. McNally and co-workers ${ }^{30}$ reported a significant reduction in EIA after oropharyngeal anaesthesia, although the responses in individual subjects were very variable. This would support a dominant role for the vagus, but our results and the similar findings of others, ${ }^{16} 1731$ argue against such a straightforward pathway in many subjects.

Attention on non-vagal mechanisms has centred on the role of the mast cell. Indirect evidence for mast cell involvement is provided by the effect of sodium cromoglycate in blocking EIA. and it has been suggested that cooling of the airways could lead directly to mediator release from superficial airway mast cells. ${ }^{28}$ Mediators such as histamine could then act directly on bronchial smooth muscle, or reflexly through vagal irritant receptors, or both.

Although our study has shown that some individuals have a vagal component to their EIA, not demonstrable by conventional bronchodilator doses of IB, we have only found this in half of our subjects. Mast cell involvement is an attrac- tive alternative, but there is no satisfactory directo evidence at present to implicate the involvemento of mediator substances. Further studies on mediator release, and the effect of specifico mediator antagonists, may provide it.

We wish to thank Dr GS Kilpatrick, Dr A $\vec{\circ}$ Seaton, and Dr AP Smith for allowing us to study patients under their care, and Mrs PH Robertso for typing the manuscript. Boehringer Ingelheim Ltd kindly supplied the ipratropium bromide.

\section{References}

1 Yu DYC, Galant SP, Gold WM. Inhibition of antigen-induced bronchoconstriction by atropine $\overrightarrow{-}$ in asthmatic patients. J Appl Physiol 1972; 32:D 823-8.

2 Orehek J, Gayrard P, Grimaud C, Charpin J. The role of SCH 1000 MDI in preventing changes in SRaw following grass pollen challenge in allergic asthmatics. Postgrad Med J 1975; 51: $\overrightarrow{0}$ suppl 7, 105.

3 Simonsson BG, Jacobs FM, Nadel JA. Role of autonomic nervous system and the cough reflexo in the increased responsiveness of airways in patients with obstructive airways disease. J Clinō Invest $1967 ; 46: 1812-8$.

4 Jones RS, Wharton MJ, Buston MH. The plar $\frac{\mathbb{8}}{2}$ of physical exercise and bronchodilator drugs in $\Rightarrow$ the assessment of the asthmatic child. Arch Dis윽 Child 1963; 38:539-45.

5 McNeill RS, Nairn JR, Millar JS, Ingram CG Exercise-induced asthma. $Q J$ Med 1966; 35: 55-67.

6 Sly RM, Heimlich EM, Busser RJ, Strick L.을 Exercise-induced bronchospasm: Effect of adren-x ergic or cholinergic blockade. J Allergy 1967;윽 40:93-9.

7 Crompton GK. An unsual example of exerciseinduced asthma. Thorax 1968; 23:165-7.

8 Simonsson BC, Skoogh BE, Ekström-Jodal B.o Exercise-induced airways constriction. Thorax 1972; 27:169-80.

9 Godfrey S. König P. Inhibition of exerciseinduced asthma by different pharmacological $\tilde{O}_{0}$ pathways. Thorax 1976; 31:137-43.

10 Tinkelman DG, Cavanaugh MJ, Cooper DM. N Inhibition of exercise-induced bronchospasm by atropine. Am Rev Repir Dis 1976; 114:87-94.

11 Engelhardt A, Klupp H. The pharmacology ando toxicology of a new tropane alkaloid derivative. Postgrad Med J 1975; 51: suppl 7, 82-5.

12 Offermeier J. In vitro action of SCH 1000 against various spasmogens. Postgrad Med J 1975; 51:0 suppl 7, 103-5.

13 Poppius H, Salorinne Y, Viljanen AA. Inhalation $\frac{?}{\mathbb{C}}$ of a new anticholinergic drug. SCH 1000, in asthma and chronic bronchitis: effect on airwaye 
resistance, thoracic gas volume, blood gases and exercise-induced asthma. Bull Physiopathol Respir 1972; 8:643-52.

14 Poppius H, Salorinne Y. Comparative trial of salbutamol and an anticholinergic drug, $\mathrm{SCH}$ 1000 , in prevention of exercise-induced asthma. Scand J Respir Dis 1973; 54:142-7.

15 Borut TC, Tashkin DP, Fischer TJ et al. Comparison of aerosolized atropine sulfate and $\mathrm{SCH}$ 1000 on exercise-induced bronchospasm in children. J Allergy Clin Immunol 1977; 60:127-33.

16 McFadden ER, Ingram RH, Haynes RL, Wellman JJ. Predominant site of flow limitation and mechanisms of postexertional asthma. $J \mathrm{Appl}$ Physiol 1977; 42:746-52.

17 Thomson NC, Patel KR, Kerr JW. Sodium cromoglycate and ipratropium bromide in exercise-induced asthma. Thorax 1978; 33:694-9.

18 Benson MK. Bronchial hyperreactivity. $\mathrm{Br} \mathrm{J} \mathrm{Dis}$ Chest 1975; 69:227-39.

19 Miller GJ, Davies BH, Cole TJ, Seaton A. Comparison of the bronchial response to running and cycling in asthma using an improved definition of the response to work. Thorax 1975; 30:306-11.

20 Hartley JPR, Charles TJ, Seaton A. Betamethasone valerate inhalation and exercise-induced asthma in adults. Br J Dis Chest 1977; 71:253-8.

21 Andersen KL, Shephard RJ, Denolin H, Varnauskas E, Masironi R. Fundamentals of exercise testing. Geneva: World Health Organisation, 1971.

22 Cotes JE, Lung function: assessment and application in medicine. Third edition. Oxford: Blackwell well Scientific, 1975.

23 Wallace E, Grieco MH. Double-blind cross-over study of cromolyn sodium inhibition of exerciseinduced bronchospasm in adults. Ann Allergy 1976; 37:153-63.

24 Fish JE, Rosenthal RR, Summer WR, Menkes $H$, Norman PS, Permutt $S$. The effect of atropine on acute antigen-mediated airway constriction in subjects with allergic asthma. Am Rev Respir Dis 1977; 115:371-9.

25 Tashkin DP, Katz RM, Kerschnar H, Rachelefsky GS, Siegel SC. Comparison of aerosolized atropine, isoproteronol, disodium cromoglycate and placebo in the prevention of exercise-induced asthma. Ann Allergy 1977; 39:311-8.

26 Kiviloog J. The effect of pretreatment with atropine in exercise-induced bronchoconstriction. Pediatrics 1975; 56:940-1.

27 Chan-Yeung M. The effect of SCH 1000 and disodium cromoglycate on exercise-induced asthma. Chest 1977; 71:320-3.

28 Zeballos RJ, Shturman-Ellstein R, McNally JF, Hirsch JE, Souhrada JF. The role of hyperventilation in exercise-induced bronchoconstriction. Am Rev Respir Dis 1978; 118:877-84.

29 Deal EC, McFadden ER, Ingram RH, Strauss RH, Jaeger JJ. Role of respiratory heat exchange in production of exercise-induced asthma. $J \mathrm{Appl}$ Physiol 1979; 46:467-75.

30 McNally JF, Enright P, Souhrada JF. The role of the oropharynx in exercise-induced bronchoconstriction. Am Rev Respir Dis 1978; 117:372a.

31 Deal EC, McFadden ER, Ingram RH, Jaeger JJ. Effects of atropine on potentiation of exerciseinduced bronchospasm by cold air. J A ppl Physiol 1979; 45:238-43. 